\title{
A Critical Role for the IL-1 Receptor in Lung Injury Induced in Neonatal Rats by $60 \% \mathrm{O}_{2}$
}

\author{
BEN-HUR JOHNSON, MAN YI, AZHAR MASOOD, ROSETTA BELCASTRO, JUN LI, SAMUEL SHEK, CRYSTAL KANTORES, \\ ROBERT P. JANKOV, AND A. KEITH TANSWELL
}

Canadian Institutes of Health Research Group in Lung Development [A.K.T.] and Physiology and Experimental Medicine [R.B., J.L., S.S., A.K.T.], Hospital for Sick Children Research Institute, Toronto, Ontario M5G 1X8, Canada; Department of Clinical Integrative Biology Programme [R.P.J., C.K.], Sunnybrook Research Institute, Toronto, Ontario M4N 3M5, Canada; Departments of Paediatrics [B.-H.J., R.P.J., A.K.T., M.Y.] and Physiology [A.M., B.-H.J., R.P.J., A.K.T.], University of Toronto, Toronto, Ontario M5S 1A8, Canada

\begin{abstract}
IL-1 $\beta$, a proinflammatory cytokine, may contribute to the development of the chronic neonatal lung injury, bronchopulmonary dysplasia. Chronic neonatal lung injury was induced in rats, by exposure to $60 \% \mathrm{O}_{2}$ for $14 \mathrm{~d}$ from birth, to determine whether pulmonary IL-1 expression was up-regulated and, if so, whether a daily s.c. IL-1 receptor antagonist injections would be protective. Exposure to $60 \% \mathrm{O}_{2}$ for $14 \mathrm{~d}$ caused pulmonary neutrophil and macrophage influx, increased tissue fraction and tyrosine nitration, reduced VEGF-A and angiopoietin-1 expression, and reduced small vessel $(20-65 \mu \mathrm{m})$ and alveolar numbers. Lung IL- $1 \alpha$ and $-1 \beta$ contents were increased after a 4-d exposure to $60 \% \quad \mathrm{O}_{2}$. IL-1 receptor antagonist treatment attenuated the $60 \% \mathrm{O}_{2}$-dependent neutrophil influx, the increased tissue fraction, and the reduced alveolar number. Treatment did not restore VEGF-A or angiopoietin-1 expression and only partially attenuated the reduced vessel number in $60 \% \mathrm{O}_{2}$-exposed pups. It also caused a paradoxical increase in macrophage influx and a reduction in small vessels in air-exposed pups. We conclude that antagonism of IL-1-mediated effects can, in major part, protect against lung injury in a rat model of $60 \% \mathrm{O}_{2}$-induced chronic neonatal lung injury. (Pediatr Res 66: 260-265, 2009)
\end{abstract}

$\mathrm{B}$ ronchopulmonary dysplasia (BPD) is a chronic neonatal lung injury (CNLI), which occurs in preterm infants delivered before 32-wk gestation. The pathologic features of BPD in the modern era are lung interstitial thickening and an inhibition or arrest of alveolar formation (1). Severe disease can be associated with pulmonary hypertension (2) and vascular pruning (3). The factors contributing to the development of BPD have not been completely elucidated, but there has been a significant progress in unraveling the molecular mechanisms involved (4).

It has been suggested that inflammation and proinflammatory cytokines play a central role in the development of BPD (5). Consistent with this was the observation that maternal chorioamnionitis was associated with an increased risk of the development of BPD after delivery (6), although a subsequent

Received March 27, 2009; accepted April 23, 2009

Correspondence: A. Keith Tanswell, MB, Division of Neonatology, The Hospital for Sick Children, Toronto, ON M5G 1X8, Canada; e-mail: keith.tanswell@sickkids.ca

Supported by group Grant MGC-25029 (to A.K.T.) and operating Grants MOP-74506, MOP-84290 (to R.P.J.), and MOP-15276 (to A.K.T.) from the Canadian Institutes of Health Research (CIHR) and an infrastructure grant from the Canada Foundation for Innovation New Opportunities Fund (to R.P.J). R.P.J. is in receipt of a CIHR New Investigator award. study did not confirm this observation (7). Elevated concentrations of IL- $1 \beta,-6$, and -8 in amniotic fluid from pregnancies complicated by chorioamnionitis have been linked to the development of BPD (8). Mice conditionally overexpressing IL-1 $\beta$ during the perinatal period have an impaired alveolar formation and a lung pathology resembling BPD (9).

The cumulative evidence is consistent with a causative role for IL- $1 \beta$ overexpression in CNLI. However, the evidence is indirect, and intervention studies are required to confirm a critical role. The IL-1 receptor (IL-1R) has three natural ligands: IL- $1 \alpha$, IL- $1 \beta$, and IL-1 receptor antagonist (IL-1Ra). A signal is transduced after binding of IL- $1 \alpha$ and IL- $1 \beta$ but not after binding of IL-1Ra. We, therefore, undertook an intervention study using a soluble IL-1Ra, to block the IL-1R $(10-13)$, in a rat model of CNLI induced by a 14-d exposure to $60 \% \mathrm{O}_{2}$. This model, as in the human infant with BPD, demonstrates a lung pathology characterized by interstitial thickening, impaired alveolar development, influxes of neutrophils and macrophages, and pulmonary hypertension $(14,15)$. The pulmonary hypertension is macrophage influxdependent (15). We have subsequently presented preliminary evidence that this pulmonary hypertension is associated with a loss of small vessels in the lung, and that the macrophage influx is initiated by a preceding neutrophil influx (Yi M et al., Inhibition of neutrophil influx protects against vessel loss in $60 \%$ oxygen-induced neonatal rat lung injury, 2008 PAS Annual Meeting, May 2-6, Honolulu, Abstract 4850.3). The interstitial thickening and impaired alveolar development are neutrophils influx-dependent, but not macrophage influxdependent $(15,16)$. In the latter study $(16)$, neutrophil influx, which was established by $\mathrm{d} 4$ of exposure, was prevented by the use of a selective CXC chemokine receptor-2 antagonist, which prevented binding of cytokine-induced neutrophil chemoattractant-1 (CINC-1) to neutrophils. Adult type II pneumocytes secrete CINC-1 in response to an IL- $1 \beta$ challenge in vitro, but not to ozone (17), making it difficult to predict how the neonatal lung exposed to $60 \% \mathrm{O}_{2}$ would respond in vivo.

Abbreviations: Ang-1, angiopoietin-1; BPD, bronchopulmonary dysplasia; CNLI, chronic neonatal lung injury; Flt-1, Fms-related tyrosine kinase-1; IL-1Ra, soluble IL-1 receptor antagonist; MCP-1, macrophage chemotactic protein-1; MIP-1, macrophage inflammatory protein-1 

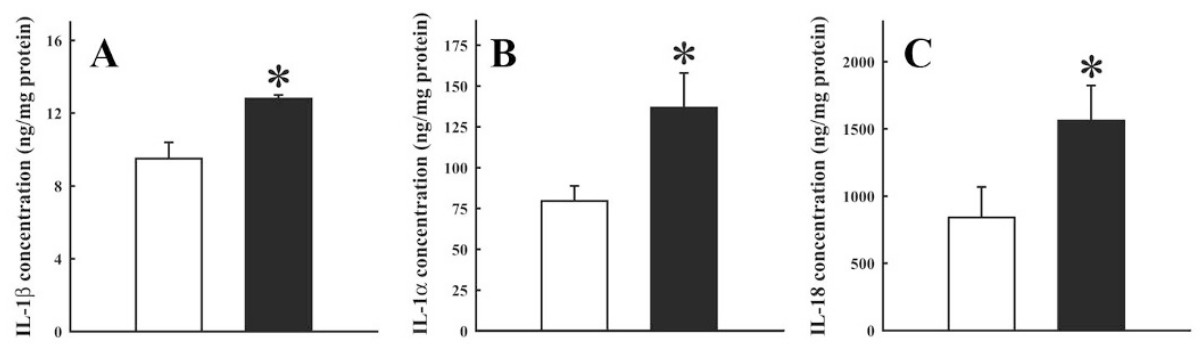

Figure 1. (A) IL-1 $\beta$, (B) IL- $1 \alpha$, and $(C)$ IL-18 concentrations in neonatal rats exposed to air (open bars) or $60 \% \mathrm{O}_{2}$ (solid bars) for $4 \mathrm{~d} . * p<0.05$ by one-way ANOVA compared with values for pups exposed to air. Values are means \pm SEM for lung homogenates from four different litters. Each homogenate was prepared from 10 to 12 pups within an individual litter.

\section{METHODS}

In vivo interventions. Animal experiments were approved by the Animal Care Review Committees of the Sunnybrook and Hospital for Sick Children Research Institutes and complied with Canadian Council for Animal Care guidelines. Rat pups (10-12/litter) were exposed to $60 \% \mathrm{O}_{2}$ or air in paired chambers for up to $14 \mathrm{~d}(14-16,18,19)$. Pups delivered inside the exposure chambers. Dams were exchanged daily between chambers to avoid maternal $\mathrm{O}_{2}$ toxicity. Pups were injected daily with $500 \mathrm{mg} / \mathrm{kg}(150 \mathrm{mg} / \mathrm{mL})$ s.c. pharmaceutical grade recombinant human IL-1Ra (Kineret, Amgen, Thousand Oaks, CA) or normal saline vehicle. This dose was based on a previous study in rodents, which found it to be nontoxic and well tolerated (20).

Cytokine assays. The initial screening for IL- $1 \beta$ was conducted on lung homogenates using a rat-specific multiplex assay kit (Linco Research, St. Charles, MO) and a Luminex ${ }^{100}$ analyzer (Luminex, Austin, TX) according to the manufacturers' instructions. The screening assay of multiple cytokines was to allow the formulation of alternative strategies should IL- $1 \beta$ synthesis not be increased. The samples for screening were, in the first instance, from pups that had been exposed to air or $60 \% \mathrm{O}_{2}$ for $4 \mathrm{~d}$, based on the previous observations that the inflammatory response, as assessed by neutrophil- and macrophage-derived reactive oxygen species, was well established by $\mathrm{d} 7$ (21). Because IL- $1 \beta$ synthesis was altered at $4 \mathrm{~d}$, testing at further time points was not necessary.

Immunohistochemistry. Perfusion fixation of lungs was at a constant inflation pressure of $20 \mathrm{~cm}$ water. Left lung blocks were randomly oriented for cutting of 5- $\mu \mathrm{m}$ sections. An avidin-biotin-peroxidase complex method (22) was used for immunostaining. Slides were incubated with the primary antibody overnight at $4^{\circ} \mathrm{C}$. Sections were incubated with biotin-conjugated secondary antibody for $1 \mathrm{~h}$, following which the labeled Vectastain ABC system (Vector Laboratories, Burlingame, CA) was used with a substrate of 3,3'-diaminobenzidine (Peroxidase Substrate kit, DAB, Vector Laboratories). Mounting of slides was in Permount mounting medium. Immunostaining was with 1:1000 primary rabbit polyclonal antibody to myeloperoxidase (Dako Canada, Mississauga, ON) to identify neutrophils (16), with a 1:100 mouse anti-rat CD-68 antibody (Serotec, Oxford, UK) to identify macrophages (23) and with a 1:2600 goat polyclonal antibody (Elastin Products, Owensville, MO) to elastin for identification of secondary crests. Secondary speciesspecific antibody concentrations were 1:200 for myeloperoxidase, CD-68, and elastin. Counter staining was with Methyl Green for myeloperoxidase, Nuclear Red for CD-68, and Carazzi hematoxylin for elastin.

Protein assay. Protein contents of homogenates were measured as described by Bradford (24).

Myeloperoxidase assay. Quantitation of myeloperoxidase activity, as a measure of pulmonary neutrophil content (25), was by colorimetric assay, as described previously (16).

Western analyses. Western blots of frozen lysates from perfused lung tissue were performed as previously described (26). Protein bands were quantified by enhanced chemiluminescence detection (15). Integrated band densities were calculated after subtraction of background values (15). Membranes were incubated overnight at $4{ }^{\circ} \mathrm{C}$ with a 1:500 dilution of rabbit anti-rat macrophage chemotactic protein-1(MCP-1; Upstate Biotechnology) or 1:100 dilutions of goat anti-murine macrophage inflammatory protein- $1 \alpha$ (MIP-1 $\alpha$ ) and MIP-1 $\beta$ (Santa Cruz Biotechnology). As an internal control, glyceraldehyde 3-phosphate dehydrogenase (GAPDH) was detected using a 1:500 dilution of a rabbit polyclonal antibody to GAPDH (Santa Cruz, Biotechnology). After washing, the membranes were incubated with a horseradish peroxidase-conjugated donkey anti-goat $\operatorname{IgG}$ secondary antibody at a 1:2000 dilution or a horseradish peroxidase-conjugated goat anti-rabbit IgG secondary antibody (Cell Signaling Technology) at a 1:2000 dilution, for $1 \mathrm{~h}$.

ELISA. Quantitation of nitrotyrosine content, as an index of peroxynitritemediated reactions, was performed using a kit (Cayman, Ann Arbor, MI), as was quantitation of angiopoietin-1 (Ang-1), VEGF-A and its receptor, Fmsrelated tyrosine kinase-1 (Flt-1; R\&D Systems, Minneapolis, MN).
Hart's elastin stain for counting small vessels. Paraffin-embedded tissue sections were stained using Weigert's resorcin-fuchsin solution (Elastin Products Co.) diluted in $70 \%$ (vol:vol) acidic ethanol. Sections were dewaxed and rehydrated, then rinsed in distilled water and placed in Weigert's solution overnight. Slides were washed in lukewarm tap water for $10 \mathrm{~min}$, then counterstained with $0.5 \%$ (wt:vol) tartrazine in $0.25 \%$ (vol:vol) acetic acid and rinsed in distilled water. Sections were then dehydrated and cleared in xylene, and mounted using a permount:xylene (1:1, vol:vol) mixture. Concentric rings with diameters of 20 and $65 \mu \mathrm{m}$ were superimposed on images. Only those vessels with both inner and outer elastic lamina, to identify arterioles, and with outer elastin band diameters within this range, were counted. The numbers of arterioles of 20-65 $\mu \mathrm{m}$ in diameter were counted in 10 random nonoverlapping fields/lung. Fields containing no identifiable arterioles were included in the analysis.

Morphometric analyses. Postfixation lung volumes were measured by water displacement. Morphometric assessments were performed as described previously $(16,19,27)$ on coded images $(\times 200)$ of 5 - $\mu \mathrm{m}$ hematoxylin and eosin-stained sections. From nonoverlapping fields, 10 random images were captured from each section, with four randomly oriented sections per animal and four animals per group. To determine tissue fraction and secondary crest volume density, a 130-point contiguous counting grid was superimposed on each image $(\times 200)$. The number of points that fell on tissue, relative to the total number of points, was used to derive the tissue fraction. The number of points that fell on secondary crests and all tissue were expressed as secondary crest/tissue ratios. Estimated total alveolar numbers were calculated as described by Weibel and Gomez (28).

Data presentation. Values are presented as mean \pm SEM. Statistical analyses were by one-way ANOVA, followed by the Holm-Sidak post hoc test for between-group differences, using the SigmaStat (SPSS Inc., Chicago, IL) analysis program. A $p$ value $<0.05$ was required for statistical significance.

\section{RESULTS}

Protein content of lung homogenates. No differences were found between the groups (data not shown).

Impact of exposure to $60 \% \mathrm{O}_{2}$ on lung cytokines content. The initial screening study using d-4 lung homogenates to determine whether expression of IL- $1 \beta$ was up-regulated in this model confirmed that it was, as were IL- $1 \alpha$ and the structurally related cytokine, IL-18 (Fig. 1). At the single time-point studied, there were no statistically significant changes in the expression of IL-2, -4, -5, -6, -10, 12p70, MCP-1, or tissue necrosis factor- $\alpha$.

Effect of injected IL-1Ra on lung and body weights and lung volumes. As shown in Table 1, a 14-d exposure to $60 \%$ $\mathrm{O}_{2}$ caused a significant reduction in lung/body weight ratio, which was prevented by treatment with IL-1Ra. Neither lung weights nor postfixation lung volumes differed significantly between the groups.

Effect of injected IL-1Ra on phagocyte influx and tyrosine nitration. Treatment with IL-1Ra did affect the neutrophil influx into the lung induced by $60 \% \mathrm{O}_{2}$, as was evident by qualitative assessment using direct microscopy (Fig. $2 A$ ) and by quantitative assessment using a myeloperoxidase assay of lung homogenates (Fig. 2B). Treatment with IL-1Ra appar- 
Table 1. Lung weight $(L W)$, body weight $(B W)$, and postfixation displacement lung volumes $(L V)$ of rat pups that had been exposed to air or $60 \% \mathrm{O}_{2}$ for $14 \mathrm{~d}$ from birth and injected daily with IL-1Ra or vehicle

\begin{tabular}{lcccc}
\hline \multicolumn{1}{c}{ Analysis } & $\begin{array}{c}\text { Air }+ \text { vehicle } \\
(\text { mean } \pm \text { SEM })\end{array}$ & $\begin{array}{c}\text { Air }+\mathrm{IL}-1 \mathrm{Ra} \\
(\text { mean } \pm \mathrm{SEM})\end{array}$ & $\begin{array}{c}60 \% \mathrm{O}_{2}+\text { vehicle } \\
(\text { mean } \pm \mathrm{SEM})\end{array}$ & $\begin{array}{c}60 \% \mathrm{O}_{2}+\mathrm{IL}-1 \mathrm{Ra} \\
(\mathrm{mean} \pm \mathrm{SEM})\end{array}$ \\
\hline $\mathrm{LW}(\mathrm{mg})$ & $490 \pm 15$ & $463 \pm 20$ & $447 \pm 8$ & $457 \pm 24$ \\
$\mathrm{BW}(\mathrm{g})$ & $25.67 \pm 0.26$ & $27.96 \pm 0.40^{*}$ & $26.69 \pm 0.20$ & $27.43 \pm 0.36 *$ \\
$\mathrm{LW} / \mathrm{BW}$ ratio $\times 10^{-2}$ & $2.04 \pm 0.09$ & $1.92 \pm 0.07$ & $1.66 \pm 0.04 *$ & $1.79 \pm 0.77$ \\
$\mathrm{LV}(\mu \mathrm{L})$ & $1020 \pm 30$ & $1039 \pm 110$ & $1000 \pm 39$ & $1010 \pm 59$ \\
\hline
\end{tabular}

$n=12$ pups from two litters (BW groups), six pups from two litters (LW and LW/BW groups), or four pups from two litters (LV) in each group.

$* p<0.05$ by one-way ANOVA of variance compared with vehicle group in air.
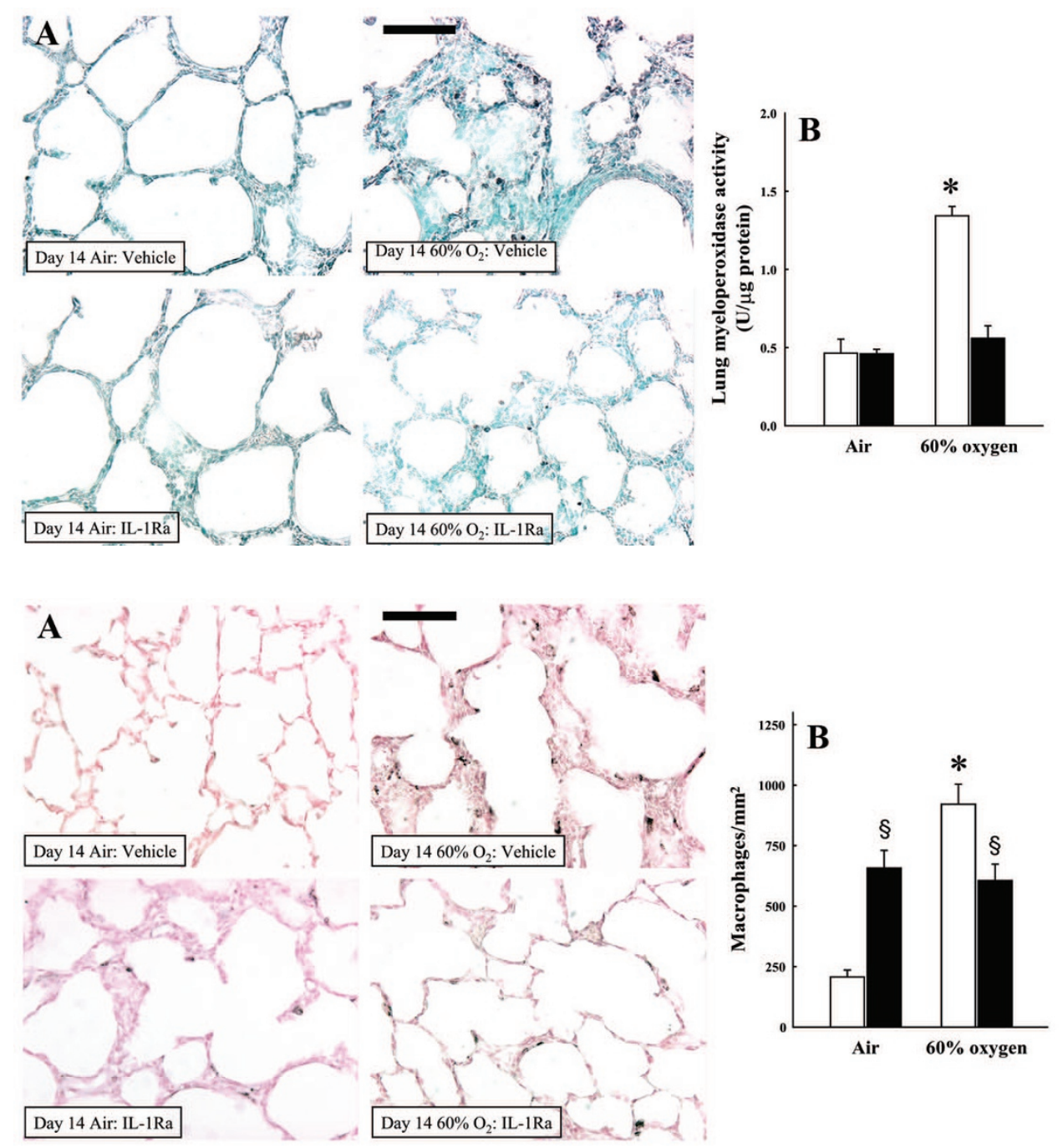

Figure 2. Lung neutrophil accumulation in neonatal rats injected with vehicle or IL-1Ra while exposed to air or $60 \% \mathrm{O}_{2}$ for 14 d. (A) Myeloperoxidase immunoreactivity (black stain) was used to illustrate the presence of neutrophils. Bar $=100$ $\mu \mathrm{m}$. (B) Myeloperoxidase activity in lung homogenates was used to quantify pulmonary neutrophil influx in vehicle-treated (open bars) or IL-1Ra-treated (solid bars) pups. $* p<0.05$ by one-way ANOVA compared with values for pups exposed to air. Values are means \pm SEM for lung homogenates from four different litters. Each homogenate was prepared from 10 to 12 pups within an individual litter. ently not only limited the macrophage influx induced by $60 \%$ $\mathrm{O}_{2}$ but also increased the influx in air-exposed pups (Fig. 3A), which was confirmed by direct cell counts, as no colorimetric assay for macrophage influx was available (Fig. 3B). When the known macrophage chemoattractants MCP-1, MIP- $1 \alpha$, and MIP-1 $\beta$ (29) were analyzed in lung homogenates by Western blot, the band for MIP- $1 \alpha$ was so faint that it could not be quantified. Treatment of air-exposed pups with IL-1Ra did not result in any increased expression of MCP-1 or MIP- $1 \beta$ on $\mathrm{d} 4,7$, or 14 of life (data not shown). Consistent with the observed changes in macrophage influx were alterations in tyrosine nitration, which, in this model, is macrophage-dependent (15). Exposure to $60 \% \mathrm{O}_{2}$ resulted in a signif- icant increase in tyrosine nitration, as reported previously (15), which was not attenuated by concurrent treatment with IL-1Ra (Fig. 4).

Effect of injected IL-1Ra on lung structure. Treatment with IL-1Ra also seemed to have an impact on the histology of the $60 \% \mathrm{O}_{2}$-exposed lung (Figs. 2 and 3). As assessed by morphometry, the increase in tissue fraction observed after exposure to $60 \% \mathrm{O}_{2}$ was prevented by treatment with IL-1Ra (Fig. 5A). Exposure to $60 \% \mathrm{O}_{2}$ resulted in a lesser alveolar density, which was not statistically significant, although concurrent treatment with IL-1Ra resulted in a significant increase in alveolar density over that observed in lungs of vehicleinjected animals exposed to $60 \% \mathrm{O}_{2}$ (Fig. $5 B$ ). There was a 


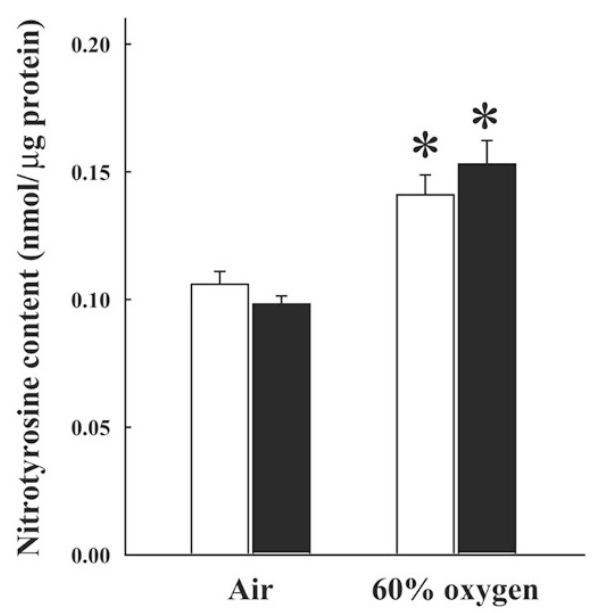

Figure 4. Lung nitrotyrosine contents of neonatal rats injected with vehicle (open bars) or IL-1Ra (solid bars) while exposed to air or $60 \% \mathrm{O}_{2}$ for $14 \mathrm{~d}$. $* p<0.05$ by one-way ANOVA compared with values for all other groups. Values are means \pm SEM for $4-6$ average sized pups from each of four different litters.
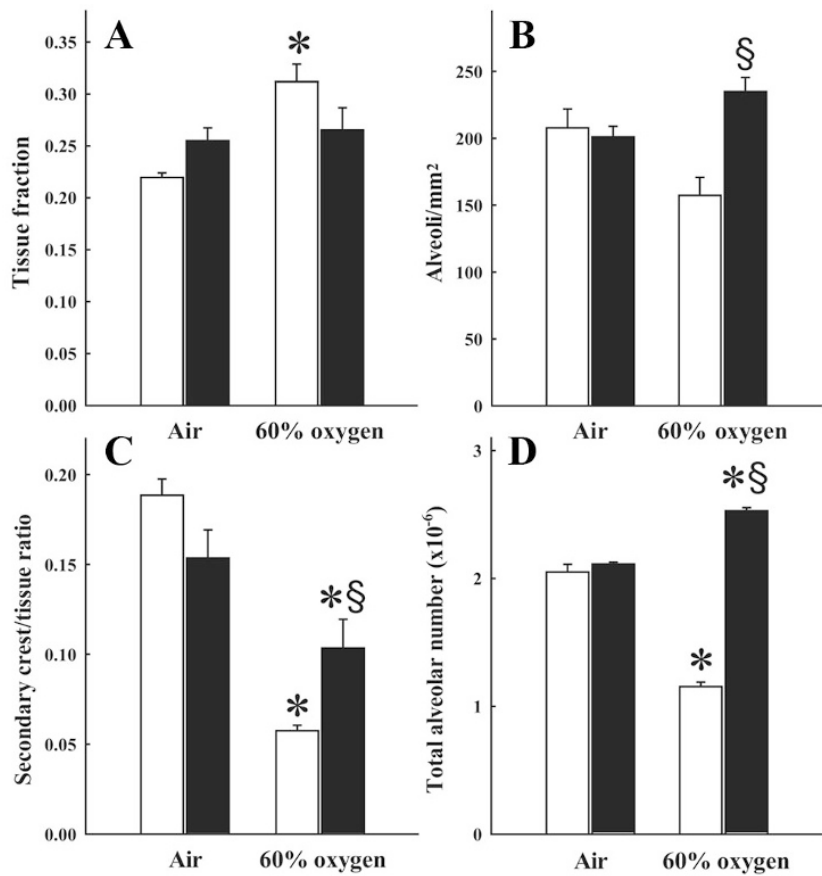

Figure 5. Morphometric analysis of lungs from neonatal rats injected with vehicle (open bars) or IL-1Ra (solid bars) while exposed to air or $60 \% \mathrm{O}_{2}$ for 14 d: $(A)$ tissue fraction; $(B)$ alveolar density; $(C)$ secondary crest-to-tissue ratio; $(D)$ estimated total alveolar number. $* p<0.05$ by one-way ANOVA compared with values for vehicle-treated pups exposed to air. $\$ p<0.05$ by one-way ANOVA compared with values for vehicle-treated pups exposed to $60 \% \mathrm{O}_{2}$. Values are means \pm SEM for $4-6$ average sized pups from each of four different litters.

significantly smaller secondary crest-to-tissue ratio after exposure to $60 \% \mathrm{O}_{2}$, which was significantly, but incompletely, prevented by concurrent treatment with IL-1Ra (Fig. 5C). That this prevention was incomplete, despite this group having a normal alveolar density may be explained by some residual tissue thickening, which, although not statistically significant, was increased above control values (Fig. 5A) and was apparent under the microscope in some fields (Fig. 2). Consistent with
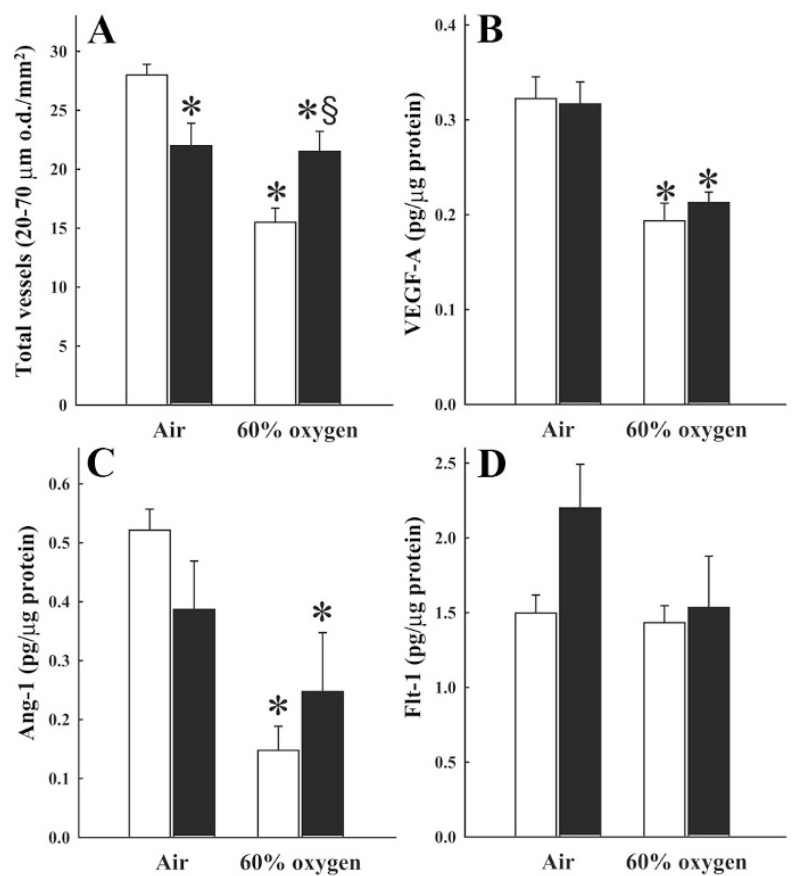

Figure 6. Lung vessel number and putative mediator contents in neonatal rats injected with vehicle (open bars) or IL-1Ra (solid bars) while exposed to air or $60 \% \mathrm{O}_{2}$ for $14 \mathrm{~d}$. (A) Vessels with outer elastin lamina of $20-65 \mu \mathrm{m}$ were counted to obtain a vessel density. Lung homogenates were assayed for their content of $(B)$ VEGF-A, $(C)$ Ang-1, and $(D)$ the VEGF receptor, Flt-1. $* p<0.05$ by one-way ANOVA compared with values for pups exposed to air. $\S p<0.05$ by one-way ANOVA compared with values for vehicle-treated pups in $60 \% \mathrm{O}_{2}$. Values are means \pm SEM for $4-6$ average sized pups from each of four different litters.

this reasoning, the significantly lower estimated total alveolar number observed after a 14-d exposure to $60 \% \mathrm{O}_{2}$ was not only completely prevented by concurrent treatment with Il-1Ra, but also exceeded the values for vehicle-treated air-exposed pups (Fig. 5D). None of the parameters measured in air-exposed pups treated with the IL-1Ra were significantly different from airexposed and vehicle-treated pups (Fig. 5A-D).

Effect of injected IL-1Ra on the number of small pulmonary vessels. The reduction in small vessel numbers after exposure to $60 \% \mathrm{O}_{2}$ was significantly attenuated by treatment with IL-1Ra, but the protection was incomplete, with small vessel numbers still being significantly below that found in air-exposed control pups (Fig. 6A). Treatment of air-exposed control pups with IL-1Ra also caused a significant decrease in small vessel numbers.

Effect of injected IL-1Ra on lung VEGF-A Ang-1 and Flt-1 concentrations. The reduced vessel numbers observed after exposure to $60 \% \mathrm{O}_{2}$ correlated with reduced concentrations of VEGF-A (Fig. 6B), Ang-1 (Fig. 6C) but not of the receptor Flt-1 (Fig. 6D). Treatment with IL-1Ra did not prevent the reduced concentrations of VEGF-A or Ang-1.

\section{DISCUSSION}

Our objective was to determine whether IL-1 expression was increased in rat CNLI and, if so, whether antagonism of the IL-1R would protect against lung injury. We did observe increased lung concentrations of both IL- $1 \alpha$ and IL- $1 \beta$ early 
in the time course of lung injury. Increased IL- $1 \beta$ has been previously reported in neonatal and adult mice $(30,31)$ and neonatal rabbits (32), exposed to $\geq 95 \% \mathrm{O}_{2}$, although its specific contribution to $\mathrm{O}_{2}$-induced lung injury was not assessed. Ventilator-induced lung injury in rats and rabbits was attenuated by treatment with an IL-1Ra $(12,13)$. Our data are consistent with activation of the IL-1R being a critical mediator of rat CNLI, but does not distinguish between IL- $1 \alpha$ and IL- $1 \beta$ as single or joint mediators of injury. Antagonism of the IL-1R completely prevented the neutrophil influx normally observed after exposure to $60 \% \mathrm{O}_{2}$ and, as previously described, when neutrophil influx was prevented by blockade of the CXC-2 receptor (16), this was associated with a reduced parenchymal thickening, an improved secondary crest formation, and an increase in alveolar number over that observed in the air-exposed control pups. Our morphometric approach does lack the precision of more elegant and sophisticated approaches currently in use (33). However, it has the advantage of simplicity, and we have found it to be well suited to demonstrate large differences between the experimental groups.

Lung macrophage content was also affected by antagonism of the IL-1R. Pups exposed to $60 \% \mathrm{O}_{2}$ had an increase in lung macrophages, as observed previously $(15,21)$, which was partially attenuated by the IL-1Ra. Pups exposed to $60 \% \mathrm{O}_{2}$ had increased nitrotyrosine formation, which was used as a marker for peroxynitrite-mediated reactions. Peroxynitrite is a potent constrictor of pulmonary arterioles (34) and could contribute to the $60 \% \mathrm{O}_{2}$-mediated reduction in small vessel number. Treatment with IL-1Ra did not attenuate the increased nitrotyrosine formation observed after exposure to $60 \% \mathrm{O}_{2}$. Given our previous findings that macrophage depletion of the lungs completely prevented $60 \% \mathrm{O}_{2}$-induced nitrotyrosine formation (15), we attribute the failure of IL-1Ra to attenuate the $60 \% \mathrm{O}_{2}$-mediated increase in nitrotyrosine formation to the incomplete suppression of the macrophage influx. The partial protection against the reduction in small vessels number observed after treatment of $60 \% \mathrm{O}_{2}$-exposed pups with IL-1Ra could also reflect a blocking effect on the action of IL- $1 \alpha$ on vascular smooth muscle to induce proliferation and an inflammatory phenotype (35). Alternatively, it may reflect a protective effect on vessel formation through an inhibition of IL- $1 \beta$ mediated reduced VEGF concentration (9). However, we found that treatment with IL1Ra offered no protection against $60 \% \mathrm{O}_{2}$-mediated reduced VEGF or Ang-1 concentrations.

The chemoattractant(s) responsible for stimulating an influx of macrophages after exposure to $60 \% \mathrm{O}_{2}$ has not yet been elucidated, but macrophage influx is well established by $\mathrm{d} 7$ of exposure (15). When studied at $\mathrm{d} 4,7$, and 14 of exposure, the whole-lung contents of MCP-1, MIP- $1 \alpha$, and MIP- $1 \beta$ were not increased in pups exposed to $60 \% \mathrm{O}_{2}$ and/or IL-1Ra. This could reflect focal increases in the injured lung not detected by whole-lung analyses or suggest the presence of alternative unmeasured macrophage chemoattractants, such as elastin fragments (36) produced by the action of neutrophil elastase. Of particular interest was the observation that air-exposed pups treated with the Il-1Ra had an unanticipated increased macrophage influx. This was not accompanied by an increased nitrotyrosine formation, at least at the single time-point studied, although a significant reduction of small vessels was observed. How antagonism of the IL-1R leads to an influx of macrophages into the lung is unclear.

An unanticipated increase in body weight was evident in both the exposure groups treated with IL-1Ra. Weight loss is associated with reduced IL-1R (37), perhaps through altered insulin sensitivity (38), and we may have simply observed a reciprocal effect.

Systemic corticosteroid therapy had been a commonly used intervention for BPD until its use was curtailed because of associated adverse neurodevelopmental outcomes (39). There is currently no effective anti-inflammatory therapy available for the treatment of BPD. Therefore, there has been considerable interest in developing novel anti-inflammatory approaches for therapeutic use in BPD, including targeting neutrophil chemokines (40). Our approach of targeting IL-1 $\beta$ binding to its receptor using IL-1Ra was highly effective in preventing lung parenchymal thickening and impairment of alveolarization and partially effective in limiting the reduction in small vessels, adding further support to the interest in developing novel specific or nonspecific anti-inflammatory interventions for CNLI.

\section{REFERENCES}

1. Coalson JJ 1999 Pathology of chronic lung disease of early infancy. In: Bland RD, Coalson JJ (eds) Chronic Lung Disease in Early Infancy. Marcel Dekker, New York, pp 85-124

2. Thibeault DW, Truog WE, Ekekezie II 2003 Acinar arterial changes with chronic lung disease of prematurity in the surfactant era. Pediatr Pulmonol 36:482-489

3. Tomashefski JF Jr, Oppermann HC, Vawter GF, Reid LM 1984 Bronchopulmonary dysplasia: a morphometric study with emphasis on the pulmonary vasculature. Pediatr Pathol 2:469-487

4. Bourbon J, Boucherat O, Chailley-Heu B, Delacourt C 2005 Control mechanisms of lung alveolar development and their disorders in bronchopulmonary dysplasia. Pediatr Res 57:38R-46R

5. de Dooy JJ, Mahieu LM, van Bever HP 2001 The role of inflammation in the development of chronic lung disease in neonates. Eur J Pediatr 160:457-463

6. Watterberg KL, Demers LM, Scott SM, Murphy S 1996 Chorioamnionitis and early lung inflammation in infants in whom bronchopulmonary dysplasia develops. Pediatrics 97:210-215

7. Andrews WW, Goldenberg RL, Faye-Petersen O, Cliver S, Goepfert AR, Hauth JC 2006 The Alabama Preterm Birth study: polymorphonuclear and mononuclear cell placental infiltrations, other markers of inflammation, and outcomes in 23- to 32-week preterm newborn infants. Am J Obstet Gynecol 195:803-808

8. Yoon BH, Romero R, Jun JK, Park JD, Ghezzi F, Kim BI 1997 Amniotic fluid cytokines (interleukin-6, tumor necrosis factor-alpha, interleukin-1 beta, and interleukin-8) and the risk for developing bronchopulmonary dysplasia. Am J Obstet Gynecol 177:825-830

9. Bry K, Whitsett JA, Lappalainen U 2007 IL-1 beta disrupts postnatal lung morphogenesis in the mouse. Am J Respir Cell Mol Biol 36:32-42

10. Park JW, Taube C, Swasey C, Kodama T, Joetham A, Balhorn A, Takeda K, Miyahara N, Allen CB, Dakhama A, Kim SH, Dinarello CA, Gelfand EW 2004 Interleukin-1 receptor antagonist attenuates airway hyperresponsiveness following exposure to ozone. Am J Respir Cell Mol Biol 30:830-836

11. Taube C, Nick JA, Siegmund B, Duez C, Takeda K, Rha YH, Park JW, Joetham A, Poch K, Dakhama A, Dinarello CA, Gelfand EW 2004 Inhibition of early airway neutrophilia does not affect development of airway hyperresponsiveness. Am J Respir Cell Mol Biol 30:837-843

12. Frank JA, Pittet JF, Wray C, Matthay MA 2008 Protection from experimental ventilator-induced acute lung injury by IL-1 receptor blockade. Thorax 63:147-153

13. Narimanbekov IO, Rozycki HJ 1995 Effect of IL-1 blockade on inflammatory manifestations of acute ventilator-induced lung injury in a rabbit model. Exp Lung Res 21:239-254

14. Han RN, Buch S, Tseu I, Young J, Christie NA, Frndova H, Lye SJ, Post M, Tanswell AK 1996 Changes in structure, mechanics, and insulin-like growth factorrelated gene expression in the lungs of newborn rats exposed to air or $60 \%$ oxygen. Pediatr Res 39:921-929

15. Jankov RP, Luo X, Belcastro R, Copland I, Frndova H, Lye SJ, Hoidal JR, Post M, Tanswell AK 2001 Gadolinium chloride inhibits pulmonary macrophage influx and prevents $\mathrm{O}_{2}$-induced pulmonary hypertension in the neonatal rat. Pediatr Res 50:172-183 
16. Yi M, Jankov RP, Belcastro R, Humes D, Copland I, Shek S, Sweezey NB, Post M, Albertine KH, Auten RL, Tanswell AK 2004 Opposing effects of 60\% oxygen and neutrophil influx on alveologenesis in the neonatal rat. Am J Respir Crit Care Med 170:1188-1196

17. Manzer R, Wang JR, Nishina K, McConville G, Mason RJ 2006 Alveolar epithelial cells secrete chemokines in response to IL-1 $\beta$ and lipopolysaccharide but not to ozone. Am J Respir Cell Mol Biol 34:158-166

18. Buch S, Han RN, Cabacungan J, Wang JX, Yuan SZ, Belcastro R, Deimling J, Jankov R, Luo XP, Lye SJ, Post M, Tanswell AK 2000 Changes in expression of platelet-derived growth factor and its receptors in the lungs of newborn rats exposed to air or $60 \% \mathrm{O}_{2}$. Pediatr Res 48:423-433

19. Padela S, Cabacungan J, Shek S, Belcastro R, Yi M, Jankov RP, Tanswell AK 2005 Hepatocyte growth factor is required for alveologenesis in the neonatal rat. Am J Respir Crit Care Med 172:907-914

20. Lim WK, Fujimoto C, Ursea R, Mahesh SP, Silver P, Chan CC, Gery I, Nussenblatt RB 2005 Suppression of immune-mediated ocular inflammation in mice by interleukin 1 receptor antagonist administration. Arch Ophthalmol 123:957-963

21. Jankov RP, Johnstone L, Robinson BH, Tanswell AK 2003 Macrophages as a major source of oxygen radicals in the hyperoxic newborn rat lung. Free Radic Biol Med 35:200-209

22. Hsu SM, Raine L, Fanger H 1981 Use of avidin-biotin-peroxidase complex (ABC) in immunoperoxidase techniques: a comparison between $\mathrm{ABC}$ and unlabeled antibody (PAP) procedures. J Histochem Cytochem 29:577-580

23. Frid MG, Brunetti JA, Burke DL, Carpenter TC, Davie NJ, Reeves JT, Roedersheimer MT, van Rooijen N, Stenmark KR 2006 Hypoxia-induced pulmonary vascular remodeling requires recruitment of circulating mesenchymal precursors of a monocyte/macrophage lineage. Am J Pathol 168:659-669

24. Bradford MM 1976 A rapid and sensitive method for the quantitation of microgram quantities of protein utilizing the principle of protein-dye binding. Anal Biochem 72:248-254

25. Goldblum SE, Wu KM, Jay M 1985 Lung myeloperoxidase as a measure of pulmonary leukostasis in rabbits. J Appl Physiol 59:1978-1985

26. Yi M, Belcastro R, Shek S, Luo D, Post M, Tanswell AK 2006 Fibroblast growth factor-2 and receptor- $1 \alpha$ (IIIc) regulate postnatal rat lung cell apoptosis. Am J Respir Crit Care Med 174:581-589

27. Padela S, Yi M, Cabacungan J, Shek S, Belcastro R, Masood A, Jankov RP, Tanswell AK 2008 A critical role for fibroblast growth factor-7 during early alveolar formation in the neonatal rat. Pediatr Res 63:232-238
28. Weibel ER, Gomez DM 1962 A principle for counting tissue structures on random sections. J Appl Physiol 17:343-348

29. Cross AK, Richardson V, Ali SA, Palmer I, Taub DD, Rees RC 1997 Migration responses of human monocyte cell lines to alpha- and beta-chemokines. Cytokine 9:521-528

30. Johnston CJ, Wright TW, Reed CK, Finkelstein JN 1997 Comparison of adult and newborn pulmonary cytokine mRNA expression after hyperoxia. Exp Lung Res 23:537-552

31. Piedboeuf B, Horowitz S, Johnston CJ, Gamache M, Belanger S, Poubelle PE, Welty SE, Watkins RH 1998 Interleukin-1 expression during hyperoxic lung injury in the mouse. Free Radic Biol Med 24:1446-1454

32. D'Angio CT, LoMonaco MB, Chaudhry SA, Paxhia A, Ryan RM 1999 Discordan pulmonary proinflammatory cytokine expression during acute hyperoxia in the newborn rabbit. Exp Lung Res 25:443-465

33. Schittny JC, Mund SI, Stampanoni M 2008 Evidence and structural mechanism for late lung alveolarization. Am J Physiol Lung Cell Mol Physiol 294:L246-L254

34. Belik J, Jankov RP, Pan J, Tanswell AK 2004 Peroxynitrite inhibits relaxation and induces pulmonary artery muscle contraction in the newborn rat. Free Radic Biol Med 37:1384-1392

35. Schultz K, Murthy V, Tatro JB, Beasley D 2007 Endogenous interleukin-1a promotes a proliferative and proinflammatory phenotype in human vascular smooth muscle cells. Am J Physiol Heart Circ Physiol 292:H2927-H2934

36. Houghton AM, Quintero PA, Perkins DL, Kobayashi DK, Kelley DG, Marconcini LA, Mecham RP, Senior RM, Shapiro SD 2006 Elastin fragments drive disease progression in a murine model of emphysema. J Clin Invest 116:753-759

37. Wong E, Freiberg M, Tracy R, Kuller I 2008 Epidemiology of cytokines: the Women On the Move through Activity and Nutrition (WOMAN) Study. Am J Epidemio 168:443-453

38. de Mello VD, Kolehmainen M, Schwab U, Mager U, Laaksonen DE, Pulkkinen I, Niskanen L, Gylling H, Atalay M, Rauvamaa R, Uusitupa M 2008 Effect of weight loss on cytokine messenger RNA expression in peripheral blood mononuclear cells of obese subjects with the metabolic syndrome. Metabolism 57:192-199

39. Committee on Fetus and Newborn 2002 Postnatal corticosteroids to treat or prevent chronic lung disease in preterm infants. Pediatrics 109:330-338

40. Auten RL, Ekekezie II 2003 Blocking leukocyte influx and function to prevent chronic lung disease of prematurity. Pediatr Pulmonol 35:335-341 